\title{
BMJ Open Non-response in a cross-sectional study of respiratory health in Norway
}

\author{
Regine Abrahamsen, ${ }^{1,2}$ Martin Veel Svendsen, ${ }^{1}$ Paul K Henneberger, ${ }^{3}$ \\ Gølin Finckenhagen Gundersen, ${ }^{1}$ Kjell Torén, ${ }^{4}$ Johny Kongerud, ${ }^{2,5}$ \\ Anne Kristin Møller Fell ${ }^{1}$
}

To cite: Abrahamsen $\mathrm{R}$, Svendsen MV, Henneberger PK, et al. Nonresponse in a cross-sectional study of respiratory health in Norway. BMJ Open 2016;6: e009912. doi:10.1136/ bmjopen-2015-009912

- Prepublication history for this paper is available online. To view these files please visit the journal online (http://dx.doi.org/10.1136/ bmjopen-2015-009912)

Received 4 September 2015 Revised 24 November 2015 Accepted 2 December 2015

CrossMark

For numbered affiliations see end of article.

Correspondence to Dr Regine Abrahamsen; regine.abrahamsen@sthf.no

\section{ABSTRACT}

Objectives: Declining participation in epidemiological studies has been reported in recent decades and may lead to biased prevalence estimates and selection bias. The aim of the study was to identify possible causes and effects of non-response in a population-based study of respiratory health in Norway.

Design: The Telemark study is a longitudinal study that began with a cross-sectional survey in 2013 .

Setting: In 2013, a random sample of 50000 inhabitants aged $16-50$ years, living in Telemark county, received a validated postal questionnaire. The response rate was $33 \%$. In this study, a random sample of 700 non-responders was contacted first by telephone and then by mail.

Outcome measures: Response rates, prevalence and $\mathrm{OR}$ of asthma and respiratory symptoms based on exposure to vapours, gas, dust or fumes (VGDF) and smoking. Causes of non-response.

Results: A total of 260 non-responders (37\%) participated. Non-response was associated with younger age, male sex, living in a rural area and past smoking. The prevalence was similar for responders and non-responders for physician-diagnosed asthma and several respiratory symptoms. The prevalence of overestimated in the Telemark study, and adjusted prevalence estimates were $17.4 \%$ and $5 \%$, respectively. Current smoking was identified as a risk factor for respiratory symptoms among responders and nonresponders, while occupational VGDF exposure was a risk factor only among responders. The Breslow-Day test detected heterogeneity between productive cough and occupational VGDF exposure among responders.

Conclusions: The Telemark study provided valid estimates for physician-diagnosed asthma and several respiratory symptoms, while it was necessary to adjust prevalence estimates for chronic cough and use of asthma medication. Reminder letters had little effect on risk factor associations. Selection bias should be considered in future investigations of the relationship between respiratory outcomes and exposures.

\section{INTRODUCTION}

Population-based studies are used to provide epidemiological data on the occurrence of chronic cough and use of asthma medication was

\section{Strengths and limitations of this study}

- The Telemark study included 16099 participants from the general population in Norway.

- Potential causes and effects of non-response due to a low response rate were identified.

- The study is strengthened by assessment of the effects of non-response on prevalence estimates as well as the exposure-outcome relationship.

- A test of homogeneity between responders and non-responders for study outcomes and potential confounders was conducted due to unequal sample sizes.

- We were unable to get in contact with $63 \%$ of the non-responders, which is a limitation of the present study but in line with similar studies.

disease and to identify possible risk factors that may affect these outcomes. ${ }^{1-6}$ In recent years, however, there has been a decline in response rates to mailed public health surveys leading to uncertainty regarding the representativeness of the population of interest. Although it is recognised that decreasing participation in epidemiological studies may increase the risk of selection bias, ${ }^{7-9}$ there are few studies assessing how exposureoutcome relationships are affected by nonresponse in particular when assessing the association between occupational exposure and respiratory effects.

The response rate is not necessarily a good predictor of non-response bias because, even though a study achieves a high response rate, the prevalence estimates might be biased if the non-response is not random. ${ }^{10-12} \mathrm{~A}$ Danish health survey examined the effect of using reminder letters to increase the response rate and reduce the possibility of bias. ${ }^{13}$ The study found that using reminder letters increased the overall response rate, but it had little effect on the prevalence estimates. A study by Groves investigated the link between non-response rates and nonresponse bias in different non-responder articles. ${ }^{11}$ Groves and colleagues summarised 
findings from several studies of non-response, and found little association between non-response rates and nonresponse bias. A few studies have compared how early responders versus late responders to the initial invitation to participate affect the prevalence of study outcomes and the results are conflicting. ${ }^{14-16}$ A study on long-term follow-up in European respiratory health studies found that the exposure-outcome associations were not necessarily affected, even though the prevalence of respiratory symptoms might be affected by the overall response rate and non-response. ${ }^{12}$

The aim of our study was to identify possible causes of non-response and its impact on estimates of the frequency of risk factors and indicators of respiratory health in a sample from the general population in Norway. The effect of using reminder letters on prevalence estimates and exposure-outcome associations was also assessed.

\section{MATERIALS AND METHODS}

\section{Study population}

The Telemark study is a longitudinal population-based study that began with a cross-sectional survey in 2013 in Telemark, Norway. Telemark county is located in the south-eastern part of Norway and has a population of approximately 170000 . Grenland is the largest region in the county with a population of 100000 . Historically, Grenland has been one of the main onshore industrialised centres in Norway. The Telemark study included a random sample of 50000 males and females aged 1650 years from the population of Telemark. Of the $50000,63 \%$ live in the urban part of Grenland and 37\% live in the rural part of the county. The sample including names, addresses and unique national ID numbers was drawn at random from the Norwegian national registry, which includes all permanent residents in Norway.

\section{Design of the Telemark study}

A prepaid envelope for returning the self-administered questionnaire was enclosed with the initial questionnaire. Participants were asked to answer questions on physiciandiagnosed asthma, respiratory symptoms, use of asthma medication, allergy, smoking habits and occupational exposure. Two reminders were sent, $1 \frac{1}{2} 2$ months and 3 months, respectively, after the initial questionnaire. The questionnaire contained validated questions based on the European Community Respiratory Health Survey (ECRHS) questionnaire and a study in western Sweden. ${ }^{6}$ The definitions of physician-diagnosed asthma and respiratory symptoms were consistent with other studies addressing asthma and asthma-like symptoms. ${ }^{6}$ 17-19

To encourage participation, a lottery with a financial incentive was conducted after the inclusion period ended. The local and national media (television, radio and newspapers) were used to spread information about the survey in connection with both the initial questionnaire and subsequent reminders. The study was also branded with a specially designed logo and patient organisations were enlisted to increase focus on the study.

Figure 1 shows the inclusion of participants for the Telemark study and the non-responder study. Of the 50000 who received the questionnaire, 1793 had moved, 4 were deceased, 13 were unable to answer due to disease or disability, 23 could not answer due to language problems and 25 had other reasons. Of the 48142 eligible participants, a total of 16099 answered the questionnaire, resulting in a response rate of $33 \%$.

\section{Design of the non-responder study}

A sample of 700 subjects was randomly selected from the 32043 non-responders in the Telemark study. Contact attempts with non-responders was first carried out by telephone and then by mail. The phone numbers for the 700 non-responders were searched for by using

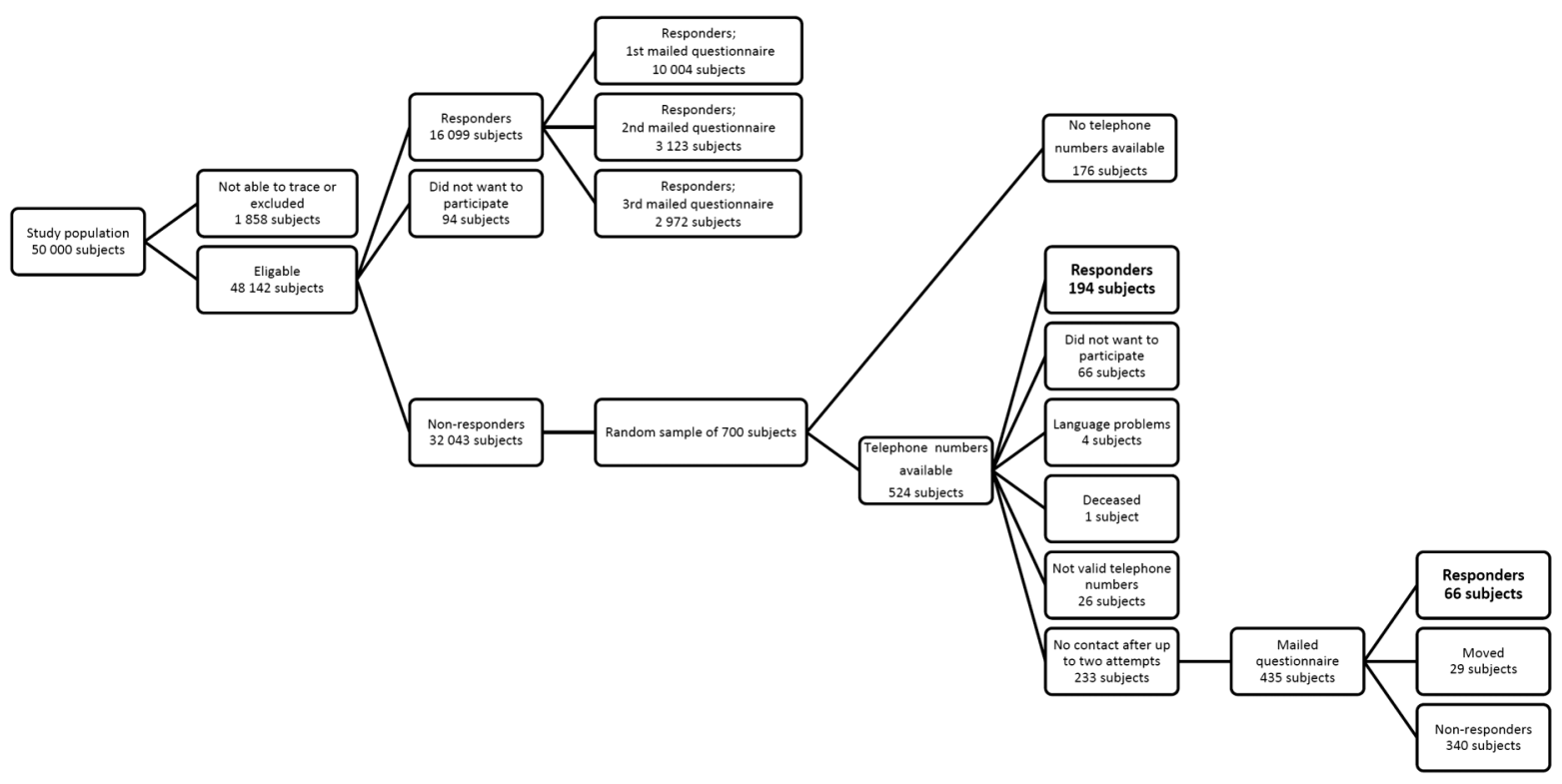

Figure 1 Flow chart of the recruitment of the Telemark study and the non-responder study. 
two commercial databases and addresses from the Norwegian national registry. The non-responders who had a valid phone number were contacted up to two times by telephone on two different occasions. Telephone interviews were conducted in January and February 2014 by two investigators; a physician and a research nurse. Verbal consent was obtained before initiating the telephone interview. The participants who did not have a valid phone number and those who did not respond to the telephone contact attempts received a questionnaire by mail in June 2014. The questionnaire included 13 questions that were identical to those used in the Telemark study. In addition, the non-responders were also asked to state the reason for not completing the initial questionnaire. All occupations for the responders and non-responders were classified according to the 1988 International Standard of Classification of Occupations (ISCO-88). ${ }^{20}$

\section{Definitions}

Physician-diagnosed asthma was defined as a positive response to the question 'Have you been diagnosed by a physician as having asthma?'. Use of asthma medication was defined as a positive response to 'Do you currently use asthma medication?'. The presence of wheezing was defined by an affirmative response to 'Have you had whistling or wheezing in the chest at any occasion during the past 12 months?'; chronic cough 'Have you had a persisting cough during recent years?'; and productive cough 'Do you usually have phlegm when coughing or do you have phlegm in the chest that is difficult to bring up?'. Nasal allergy was defined as a positive response to 'Do you have allergy that gives symptoms from the nose, including hay fever?'. Occupational exposure was defined as an affirmative answer to 'Have you ever been exposed to vapour, gas, dust or fumes at work?'. Smoking habits were defined by three questions. The first question was 'Do you smoke?'. This question was followed up with two alternatives: 'If yes, do you smoke daily or occasionally?' and 'If no, have you smoked in the past?'.

Responders and non-responders were classified according to their current self-reported occupation. ISCO-88 classifies occupations into the following 10 major groups that are related to formal education/qualification: legislators, senior officials and managers (ISCO 1), professionals (ISCO 2), technicians and associated professionals (ISCO 3), clerks (ISCO 4), service workers and shop and market sales workers (ISCO 5), skill agricultural and fishery workers (ISCO 6), craft and related workers (ISCO 7), plant and machine operator and assemblers (ISCO 8), elementary occupations (ISCO 9) and armed forces (ISCO 10).

\section{Ethics}

The Regional Committees for Medical and Health Research Ethics in Norway (REC) only allowed the Telemark study to send two reminders to the participants in the study. The committee also limited how many non-responders could be contacted and the number of contact attempts.

\section{Statistical analyses}

$\chi^{2}$ test was used to compare employment in the past 12 months, current occupation, exposure to VGDF, smoking, presence of asthma and respiratory symptoms and use of asthma medication between responders and non-responders, and between early and late responders. $\chi^{2}$ test was also used to compare participation status between genders and between area of domicile as well as reasons for non-response between males and females. The Mann-Whitney test was used to compare mean age between groups. ORs with $95 \%$ CIs for responders and non-responders were calculated by multiple logistical regression analysis adjusted for age, sex, area of domicile and smoking habits. The risk of respiratory symptoms with regard to current smoking was only adjusted for age, sex and area of domicile. The Breslow-Day statistic was used to test homogeneity of the common OR. The 16099 responders each have an initial weight of 1 , while the 260 non-responders each have an initial weight of 130.39 (to represent the 33901 non-participants). To calculate the final used weighting, the inverse sampling probability of each individual in the sample is divided by the mean of the inverse sampling probabilities of all individuals. This yields a weighting variable that is scaled such that the mean weight of all individuals is 1 and the weighted sample size equals the actual unweighted sample size. ${ }^{21}$ This resulted in a weight for the original 16099 responders of $16359 / 50.000=0.3272$ and for the non-responders of $0.3272 \times 130.39=42.66$. The weights were used to calculate estimates for OR for current smoking and occupational exposure to VGDF as risk factors for respiratory symptoms in the population. A $\mathrm{p}$ Value $<0.05$ was considered significant for all analysis. Statistical analysis was performed using IBM SPSS Statistics for Windows, V.21.0, Armonk, New York, USA.

\section{RESULTS}

\section{Participation in the Telemark study}

The population characteristics of the non-responder sample and of responders to the initial questionnaire and subsequent reminders are shown in table 1 .

The overall response rate was higher in Grenland as compared to outside Grenland, and women had a significantly higher response rate compared to men. The overall response rate was highest after the first mailed questionnaire and declined for each subsequent reminder. While the response rate among women was highest after the first mailed questionnaire and the response rate decreased for each reminder, the response rate among men increased from the second to the last reminder. The table also shows that older age was associated with responding to the initial questionnaire as compared to the reminders $(\mathrm{p}=<0.001)$. 




Participation of non-responders

The inclusion of the non-responders is shown in figure 1 . The overall response rate among the 700 non-responders was $37 \%(260 / 700)$, with more participating by telephone $(n=194)$ than by the mail $(n=66)$, and with men favouring the telephone interview more than women (table 1). Participation among non-responders was more common outside Grenland compared to within Grenland, and for men as compared to women. Non-responders were younger than participants in the Telemark study with mean ages of 34.5 versus 36 years, respectively. A total of 202 non-responders (29\%) did not have a telephone number available $(n=176)$ or did not have a valid telephone number $(n=26)$ when contact attempts were made (figure 1 ).

Prevalence of respiratory symptoms, smoking habits and occupation among responders and non-responders

Employment status in the past 12 months and the frequency of self-reported occupational exposures to vapours, gas, dust or fumes (VGDF) did not vary substantially by responder status (table 2).

The prevalence of physician-diagnosed asthma was similar among responders and non-responders, 12\% versus $11.5 \%$. The use of asthma medication was significantly more common among responders compared to non-responders $(7.5 \%$ vs $3.9 \%)$. Chronic cough was more common among responders, but this association was statistically significant only among women, with differences of $22.9 \%$ versus $13.2 \%$ and $19.3 \%$ versus $17.8 \%$ in women and men, respectively. These differences were confirmed when we modelled response and adjusted for potential confounders: OR=1.98 (95\% CI 1.05 to 3.74) among all participants for use of asthma medication, $\mathrm{OR}=2.06(95 \%$ CI 1.21 to 3.50$)$ among women and $\mathrm{OR}=1.08$ (95\% CI 0.69 to 1.70 ) among men for chronic cough. We weighted the estimates from responders and non-responders on the basis of their proportions of the entire sample to yield adjusted prevalence estimates of $17.4 \%$ for chronic cough and 5\% for use of asthma medication. The prevalence of wheezing in the past 12 months, productive cough and nasal allergies did not differ substantially by responder status. Also, the prevalence of current smoking was similar in responders and non-responders, $24 \%$ versus 24.6\%. However, past smoking was significantly less common among responders $(20.9 \%)$ compared to non-responders (29.6\%). The prevalence of physician-diagnosed asthma and respiratory symptoms did not vary among nonresponders who answered by telephone and by mail. However, there were significantly more past smokers among non-responders who responded by telephone compared to those who responded by mail, $33 \%$ versus $17 \%$, respectively.

Sixty-one per cent and $77 \%$ of responders and nonresponders, respectively, were classified by ISCO-88 according to their self-reported current occupation. There were no significant differences in occupational 
Table 2 Prevalence of employment, occupational exposure, asthma, respiratory symptoms and smoking habits among responders and non-responders

\begin{tabular}{|c|c|c|c|c|c|c|c|c|c|c|}
\hline & Response category & $N_{\text {men }}$ & Men & p Value & $\mathrm{N}_{\text {women }}$ & Women & p Value & $\mathrm{N}_{\text {total }}$ & Total & p Value \\
\hline \multirow[t]{2}{*}{ Employed in the past 12 months } & $\mathrm{R}(\%)$ & 7149 & $6020(84.2)$ & 0.095 & 8856 & $7282(82.2)$ & 0.723 & 16005 & 13302 (83.1) & 0.115 \\
\hline & NR (\%) & 136 & $122(89.7)$ & & 123 & $103(83.7)$ & & 259 & 225 (86.9) & \\
\hline \multirow[t]{2}{*}{ Ever exposed to VGDF* } & $\mathrm{R}(\%)$ & 7142 & $4525(63.4)$ & 0.928 & 8840 & 2786 (31.5) & 0.435 & 15982 & $7311(45.7)$ & 0.165 \\
\hline & NR (\%) & 134 & $86(64.2)$ & & 123 & $43(35.0)$ & & 257 & $129(50.2)$ & \\
\hline \multirow[t]{2}{*}{ Ever asthma } & $\mathrm{R}(\%)$ & 6952 & $875(12.6)$ & 0.695 & 8628 & $1262(14.6)$ & 0.302 & 15580 & $2137(13.7)$ & 0.792 \\
\hline & NR (\%) & 136 & $15(11.0)$ & & 122 & $22(18.0)$ & & 258 & 37 (14.3) & \\
\hline \multirow[t]{2}{*}{ Physician-diagnosed asthma } & $\mathrm{R}(\%)$ & 6832 & $751(11.0)$ & 0.490 & 8489 & $1090(12.8)$ & 0.588 & 15321 & $1841(12.0)$ & 0.914 \\
\hline & NR (\%) & 136 & $12(8.8)$ & & 124 & $18(14.5)$ & & 260 & $30(11.5)$ & \\
\hline \multirow[t]{2}{*}{ Use of asthma medication } & $\mathrm{R}(\%)$ & 6961 & $435(6.2)$ & 0.067 & 8650 & $736(8.5)$ & 0.328 & 15611 & $1171(7.5)$ & 0.029 \\
\hline & NR (\%) & 135 & $3(2.2)$ & & 123 & $7(5.7)$ & & 258 & $10(3.9)$ & \\
\hline \multirow[t]{2}{*}{ Wheezing in the past 12 months } & $\mathrm{R}(\%)$ & 7047 & $1380(19.6)$ & 0.444 & 8685 & $1846(21.3)$ & 0.912 & 15732 & $3226(20.5)$ & 0.761 \\
\hline & NR (\%) & 135 & $30(22.2)$ & & 123 & $25(20.3)$ & & 258 & $55(21.3)$ & \\
\hline \multirow[t]{2}{*}{ Chronic cough } & $\mathrm{R}(\%)$ & 6968 & 1342 (19.3) & 0.741 & 8628 & 1977 (22.9) & 0.012 & 15596 & 3319 (21.3) & 0.033 \\
\hline & NR (\%) & 135 & $24(17.8)$ & & 121 & 16 (13.2) & & 256 & $40(15.6)$ & \\
\hline \multirow[t]{2}{*}{ Productive cough } & $\mathrm{R}(\%)$ & 6926 & 1018 (14.7) & 0.4618 & 8536 & 1345 (15.8) & 0.456 & 15462 & 2363 (15.3) & 0.992 \\
\hline & NR (\%) & 135 & $23(17.0)$ & & 124 & $16(12.9)$ & & 259 & 39 (15.1) & \\
\hline \multirow[t]{2}{*}{ Nasal allergies } & $\mathrm{R}(\%)$ & 6982 & 2134 (30.6) & 0.508 & 8649 & 2680 (31.0) & 0.238 & 15631 & 4814 (30.8) & 0.788 \\
\hline & NR (\%) & 134 & $37(27.6)$ & & 122 & $44(36.1)$ & & 256 & $81(31.6)$ & \\
\hline \multirow[t]{2}{*}{ Never smokers } & $\mathrm{R}(\%)$ & 6994 & $3822(54.6)$ & 0.007 & 8633 & $4785(55.4)$ & 0.067 & 15627 & 8607 (55.1) & 0.001 \\
\hline & NR (\%) & 136 & 63 (46.3) & & 124 & 56 (45.2) & & 260 & 119 (45.8) & \\
\hline \multirow[t]{2}{*}{ Past smokers } & $\mathrm{R}(\%)$ & 6994 & 1438 (20.6) & & 8633 & 1833 (21.2) & & 15627 & 3271 (20.9) & \\
\hline & NR (\%) & 136 & 43 (31.6) & & 124 & $34(27.4)$ & & 260 & 77 (29.6) & \\
\hline \multirow[t]{2}{*}{ Current smokers } & $\mathrm{R}(\%)$ & 6994 & $1734(24.8)$ & & 8633 & 2015 (23.3) & & 15627 & 3749 (24.0) & \\
\hline & NR $(\%)$ & 136 & $30(22.1)$ & & 124 & $34(27.4)$ & & 260 & $64(24.6)$ & \\
\hline
\end{tabular}


groups based on responder status ( $\mathrm{p}$ value 0.30 ). However, a weak trend was observed with nonresponders reporting slightly more often 'manual' or 'blue-collar' occupations (ISCO 6-9) when compared to responders (30\% vs $24 \%)$.

\section{Causes for non-response}

The reasons for not responding to the cross-sectional questionnaire in the Telemark study are shown in table 3.

Table 3 shows that no particular reason was a more common cause for not participating among men than women (33\% vs 23\%), while lack of time was more common among women ( $17 \%$ vs $13 \%$ ). Overall, there was no significant difference between men and women regarding the causes for not responding $(\mathrm{p}=0.368)$. 'Other causes' for non-response included participants who stated that they did not understand the questions or considered the study of little relevance, and participants who reported having moved.

\section{Early responders versus late responders and non-responders}

The prevalence of physician-diagnosed asthma $(p=0.009)$, chronic cough $(p=0.012)$ and use of asthma medication $(p=0.002)$ was highest among early responders and decreased with each reminder, except for chronic cough where the prevalence increased slightly with the last reminder (figure 2). No differences were observed for productive cough $(\mathrm{p}=0.239)$, wheezing in the past 12 months $(\mathrm{p}=0.062)$ and nasal allergy $(\mathrm{p}=0.826)$. For smoking habits $(\mathrm{p}<0.001)$, the prevalence of current smoking was low among early responders and increased with each reminder. In contrast, the prevalence of never and past smoking was highest among early responders. However, for past smoking, the

Table 3 Reasons for non-responding by sex among those who completed the non-responder survey

\begin{tabular}{llll}
\hline & $\begin{array}{l}\text { Non-responder } \\
(\mathbf{n}=260)\end{array}$ & $\begin{array}{l}\text { Males } \\
(\mathbf{n}=136)\end{array}$ & $\begin{array}{l}\text { Females } \\
(\mathbf{n}=124)\end{array}$ \\
\hline $\begin{array}{l}\text { Lack of time } \\
\text { No particular }\end{array}$ & $73(15.0 \%)$ & $18(13.2 \%)$ & $21(16.9 \%)$ \\
reason & $45(33.1 \%)$ & $28(22.6 \%)$ \\
$\begin{array}{l}\text { Questionnaire } \\
\text { was too } \\
\text { extensive }\end{array}$ & $27(10.4 \%)$ & $12(8.8 \%)$ & $15(12.1 \%)$ \\
$\begin{array}{l}\text { Forgot to } \\
\text { answer }\end{array}$ & $48(18.5 \%)$ & $25(18.4 \%)$ & $23(18.5 \%)$ \\
$\begin{array}{l}\text { Did not } \\
\text { receive }\end{array}$ & $27(10.4 \%)$ & $15(11.0 \%)$ & $12(9.7 \%)$ \\
$\begin{array}{l}\text { questionnaire } \\
\text { Did not want } \\
\text { to participate }\end{array}$ & $9(3.5 \%)$ & $2(1.5 \%)$ & $7(5.6 \%)$ \\
$\begin{array}{l}\text { Not motivated } \\
\text { to participate } \\
\text { Other reasons }\end{array}$ & $10(3.8 \%)$ & $6(4.4 \%)$ & $4(3.2 \%)$ \\
\hline
\end{tabular}

prevalence was highest among the non-responders compared to early responders.

\section{Multivariate relationships}

The risk of having respiratory symptoms and asthma based on responder status is shown in table 4 .

Table 4 shows that responders had a significantly increased risk of chronic cough and use of asthma medication. The risk of wheezing, productive cough, nasal allergies and physician-diagnosed asthma did not vary by responder status.

Current smoking and occupational exposure to VGDF were identified as risk factors for productive cough, wheezing in the past 12 months and chronic cough for early responders (ER) and late responders (ER+LR1 and ER+LR1+LR2) (table 5). Current smoking was identified as a risk factor for productive and chronic cough among the non-responders.

The exposure-outcome associations were significant among early responders and did not vary substantially with additional reminders. In order to assess homogeneity among ER, LR1 and LR2 and also among responders and non-responders, the Breslow-Day statistic was used. It showed heterogeneity only for the association between productive cough and occupational VGDF exposure (table 5). To calculate how the low response rate affected these outcomes, the results from the 260 non-responders were assumed to be representative of all 33901 non-responders who did not participate in the Telemark study. All 16359 individuals who provided data (ie, 16099 responders +260 who completed the nonresponders survey) were weighted by their proportion of all invitees, or $16359 / 50.000=0.3272$. The 260 nonresponders had the additional weight of 130.39 (ie, $33901 / 260$ ) so that they would represent all nonresponders. Thus, the weights were 0.3272 for the 16099 responders and $42.66(0.3272 \times 130.39)$ for the 260 non-responders. With this correction, the weighted ORs for occupational exposure to VGDF as a risk factor for respiratory symptoms were lower compared to the ORs in the Telemark study (ER+LR1+LR2) (table 5). In contrast, the calculated ORs of current smoking on productive and chronic cough were higher compared to the ORs in the Telemark study (ER+LR1+LR2), but lower for wheezing in the past 12 months.

\section{DISCUSSION}

In a population-based study of respiratory health in Norway, we achieved a response rate of $33 \%$. Non-response was associated with younger age, being male, living in a rural area and past smoking. The prevalence was similar for responders and non-responders for physician-diagnosed asthma and several respiratory symptoms, while the prevalence for chronic cough and use of asthma medication was overestimated in the Telemark study. Current smoking was identified as a risk factor for respiratory symptoms among both responders 
Figure 2 Prevalence of physician-diagnosed asthma, respiratory symptoms and smoking habits among early responders, responders to subsequent reminders and non-responders.

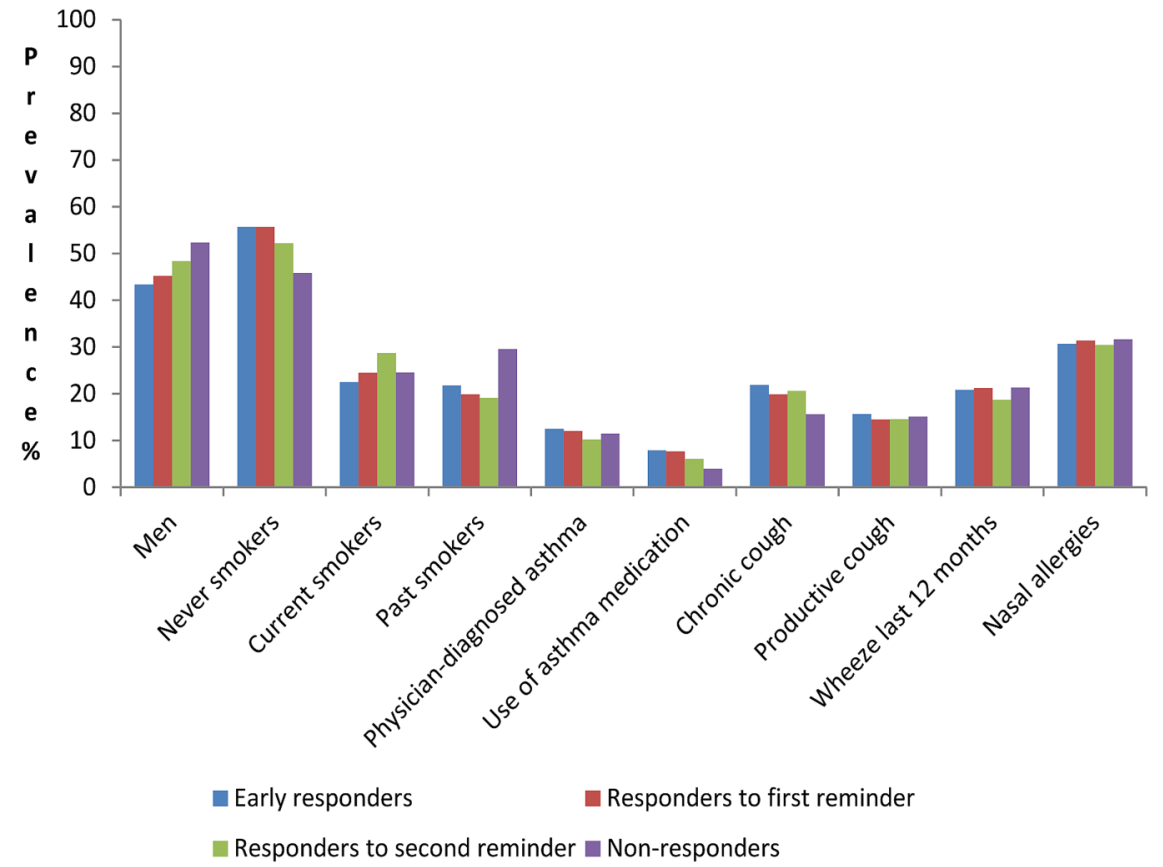

and non-responders. Exposure to VGDF at work was a risk factor for respiratory symptoms only among responders and heterogeneity in the OR estimates was identified for productive cough. These last findings indicate biased self-selection.

Of the 700 randomly selected non-responders, a total of $260(37 \%)$ were successfully contacted first by telephone and then by mail. Similar studies have shown that using different methods to contact the participants may affect study results. ${ }^{15} 22{ }^{23}$ In this study, the questions regarding physician-diagnosed asthma, respiratory symptoms and smoking habits were phrased in an identical way in the telephone interviews and in the mailed questionnaire. The prevalence of physician-diagnosed asthma and respiratory symptoms did not vary substantially by the different methods by which the nonresponders were contacted. However, there were more past smokers among the non-responders who answered by telephone compared to non-responders who answered by mail, $33 \%$ versus $17 \%$, respectively. A

Table 4 The risk of having respiratory symptoms and physician-diagnosed asthma, comparing responders to non-responders

\begin{tabular}{ll}
\hline & OR $_{\mathbf{a d j}}{ }^{{ }^{*}}$ \\
\hline Physician-diagnosed asthma & $1.07(0.73$ to 1.57$)$ \\
Use of asthma medication & $1.98(1.05$ to 3.74$)$ \\
Wheezing in the past 12 months & $0.97(0.72$ to 1.32$)$ \\
Chronic cough & $1.45(1.03$ to 2.05$)$ \\
Productive cough & $1.05(0.74$ to 1.48$)$ \\
Nasal allergies & $0.95(0.73$ to 1.24$)$ \\
\hline
\end{tabular}

${ }^{*}$ Adjusted, by using multiple logistic regression, for age, sex, area of domicile and smoking habits. possible explanation for this finding is that this group might be more aware of the negative effects of smoking since they have chosen to stop smoking. This group may not want to participate in a respiratory health survey because it will remind them that their past smoking could have contributed to respiratory problems. However, our results suggest that if this group is contacted by telephone, the reluctance to respond is lower.

Our results show that non-response was associated with younger age, male sex and living outside Grenland. Other non-responder studies from Scandinavia also report that non-response was associated with younger age and male sex. ${ }^{14} 2324$ A non-responder study from Bergen showed that non-responders were younger and of male sex, but in contrast to our study they were more likely to live in urban areas. ${ }^{25} \mathrm{~A}$ possible cause for nonresponse among younger adults in our study may be that they are studying elsewhere or completing military service but are still registered at their family home, even though they are not currently living there.

Our concern was that the relatively low response rate of $33 \%$ in the Telemark study may have led to biased prevalence estimates. We found that the prevalence of physician-diagnosed asthma and several respiratory symptoms were similar for responders and nonresponders. However, the prevalence of chronic cough $(21.3 \%$ vs $15.6 \%)$ and use of asthma medication $(7.5 \%$ vs $3.9 \%$ ) was higher among the responders. This indicates that the prevalence estimates for chronic cough and use of asthma medication were overestimated in the Telemark study and needed to be corrected to more accurately represent the whole cohort. The adjusted prevalence estimates were $17.4 \%$ for chronic cough and $5 \%$ for use of asthma medication. In a respiratory study from northern Finland, the prevalence of respiratory 
Table 5 ORs with $95 \%$ Cls for current smoking and occupational exposure to VGDF as risk factors for respiratory symptoms

\begin{tabular}{|c|c|c|c|c|c|c|c|}
\hline & $\operatorname{ER}(n=10004)$ & $\begin{array}{l}\text { ER+LR1 } \\
(n=13127)\end{array}$ & $\begin{array}{l}\text { ER+LR1+LR2 } \\
(n=16099)\end{array}$ & $\begin{array}{l}\text { Homogeneity } \\
\text { between ER/LR1/LR2 } \\
\text { ( } p \text { value) }\end{array}$ & NR $(n=260)$ & $\begin{array}{l}\text { Homogeneity } \\
\text { between LR2/NR } \\
\text { ( } p \text { value) }\end{array}$ & $\begin{array}{l}\text { Weighted* } \\
(n=16359)\end{array}$ \\
\hline \multicolumn{8}{|c|}{ Current smoking†‡ } \\
\hline $\begin{array}{l}\text { Productive } \\
\text { cough }\end{array}$ & $2.78(2.44$ to 3.16$)$ & 2.74 (2.44 to 3.07$)$ & 2.62 (2.36 to 2.90$)$ & 0.439 & 3.37 (1.44 to 7.44$)$ & 0.440 & 2.99 (2.70 to 3.31$)$ \\
\hline $\begin{array}{l}\text { Wheezing in } \\
\text { the past } \\
12 \text { months }\end{array}$ & 2.64 (2.35 to 2.96$)$ & 2.61 (2.63 to 2.89$)$ & 2.59 (2.37 to 2.84$)$ & 0.838 & 1.70 (0.83 to 3.47$)$ & 0.293 & 1.95 (1.79 to 2.14$)$ \\
\hline Chronic cough & $1.71(1.52$ to 1.92$)$ & $1.70(1.53$ to 1.88$)$ & 1.59 (1.45 to 1.74$)$ & 0.052 & $2.33(1.05$ to 5.16$)$ & 0.271 & 1.95 (1.78 to 2.15$)$ \\
\hline \multicolumn{8}{|c|}{ Occupational exposure to VGDF ever§ף } \\
\hline $\begin{array}{l}\text { Productive } \\
\text { cough }\end{array}$ & 1.59 (1.41 to 1.79$)$ & 1.59 (1.43 to 1.77$)$ & $1.73(1.57$ to 1.91$)$ & 0.003 & 1.29 (0.61 to 2.72$)$ & 0.819 & 1.39 (1.27 to 1.53$)$ \\
\hline $\begin{array}{l}\text { Wheezing in } \\
\text { the past } \\
12 \text { months }\end{array}$ & 1.63 (1.47 to 1.82$)$ & 1.63 (1.49 to 1.80$)$ & 1.70 (1.56 to 1.85$)$ & 0.106 & 1.07 (0.56 to 2.01$)$ & 0.229 & 1.21 (1.12 to 1.32$)$ \\
\hline Chronic cough & 1.40 (1.26 to 1.56$)$ & 1.41 (1.29 to 1.55$)$ & 1.47 (1.35 to 1.60$)$ & 0.061 & 1.07 (0.57 to 2.21$)$ & 0.877 & 1.18 (1.08 to 1.29$)$ \\
\hline
\end{tabular}

\section{Bold typeface represents $p$ values less than 0.05}

The calculations are based on early responders (ER), responders after the first reminder (ER+LR1), responders after the second reminder (ER+LR1+LR2), among the non-responders (NR), and weighted responses.

*Weighting the 260 non-responders by 42.66 and the 16099 responders (LR2) by 0.3272 , ensuring that the 16359 responses represent the entire study sample of 50000 .

†Compared to never-smokers.

$\ddagger$ Adjusted for age, sex and area of domicile.

$\S$ Compared to those not occupationally exposed to vapour, gas, dust or fumes.

ๆAdjusted for age, sex, area of domicile and smoking habits. 
symptoms and asthma was generally greater among responders as compared to non-responders, although the differences were not statically significant for all the symptoms. ${ }^{23}$ Except for chronic cough and use of asthma medications, our results are in agreement with other non-responder studies from Norway and Sweden that have reported that the prevalence of respiratory disorders and symptoms did not differ significantly between responders and non-responders. ${ }^{14} 25$

In this study, the prevalence of physician-diagnosed asthma, use of asthma medication, chronic and productive cough was higher among the early responders compared to late responders. The reminder letters only led to small changes in the final prevalence for most of the respiratory symptoms. These findings are in line with similar studies on respiratory health where early responders are reported to have a higher prevalence of respiratory symptoms and diseases. ${ }^{14} 1525$ For smoking habits, the prevalence of current smoking was lower among the early responders and increased for each reminder. Rönmark et $a l^{14}$ also found that current smokers were late responders and the prevalence was highest among non-responders. In our study, the prevalence of past smoking was higher for non-responders compared to early responders and late responders.

A few studies have reported that an exposureoutcome association does not need to be affected, even though the prevalence of respiratory symptoms might be affected by the overall response rate. ${ }^{12}{ }^{14}$ In our study, current smoking and exposure to VGDF at work were identified as risk factors for wheezing, productive and chronic cough. The ORs were significant among early responders and did not differ significantly compared to late responders. These results suggest that the reminder letters had little impact on the exposure-outcome associations, as the ORs did not change significantly with the reminder letters. However, heterogeneity in the relation between productive cough and VGDF were identified in responders. To assess how the low response rate affected the exposure-outcome associations, the results from the 260 non-responders were assumed to be representative of all the non-responders who did not participate in the Telemark study. With this correction, the risk of current smoking and occupational exposure to VGDF for respiratory symptoms were calculated. When we compared the results for the responders (LR2) with the calculated result, current smoking as a risk factor for productive and chronic cough will be underestimated in the Telemark study. A possible explanation for this finding is that current smokers with respiratory symptoms may choose not to participate in a respiratory health survey if they believe that their symptoms are caused by their smoking. On the other hand, occupational exposure to VGDF as a risk factor for respiratory symptoms will be overestimated in the Telemark study. On the basis of this finding, it may be assumed that participants who are exposed to VGDF at work are more likely to report respiratory symptoms compared to those who are not exposed at work. If the calculated results are representative of the whole cohort; this result may indicate the presence of selection bias since there is a possible correlation between participating in the study, occupational exposures and the presence of respiratory symptoms. This difference in exposure-outcome associations must be considered in future data analyses, and with regard to the generalisability of the study results.

All responders and non-responders were classified into occupational groups by ISCO-88 according to their selfreported current occupation. There were no significant differences in occupational groups based on responder status ( $\mathrm{p}$ value 0.30). However, a weak trend was observed with non-responders reporting slightly more often 'manual' occupations (ISCO 6-9) ${ }^{26}$ compared to responders, $30 \%$ versus $24 \%$. This difference in socioeconomic groups between non-responders and responders has been reported in similar studies. Rönmark et $a l^{24}$ found that there were significantly more manual workers among the non-responders compared to responders. Also, a study from Italy found that participants in low socioeconomic classes tended to be late responders. ${ }^{15}$

Our study has some important limitations. First, contact with $63 \%$ of the non-responders was not achieved. The telephone numbers for the nonresponders were found from two commercial databases requiring a match on either name or address. However, these databases are not national databases that are regularly updated. Therefore, $29 \%$ of the 700 nonresponders did not have a telephone number available or did not have a valid telephone number when contacted. As shown in figure 1 , of the 524 participants with available telephone numbers, we were not able to get into contact with $259(49 \%, \mathrm{n}=233+26)$. This limitation was difficult to avoid as the Regional Committees for Medical and Health Research Ethics in Norway (REC) have strict requirements in regard to how many and in what ways non-responders may be contacted. The possibility of using the internet to increase the response rate among the non-responders was also considered. A unique e-mail address would be necessary to successfully contact the non-responder, but there are no such databases available in Norway. Since merely 37\% responded, it is still possible that these participants are not representative of all those who did not participate in the Telemark study. However, there are no register-based records available on the prevalence of respiratory symptoms and diseases in Telemark for comparison of results. It was considered to be likely that the use of nationalbased registers would probably not increase the validity of the results as the national prevalence of respiratory symptoms may also differ from those in Telemark County.

Some studies have investigated how participation can be improved in epidemiological surveys. A study from Sweden investigated possible reasons for not participating in these studies and the most frequent answer 
among the non-responders was lack of time. ${ }^{14}$ When asked what could have made them participate, the suggestion was a shorter questionnaire. A systematic review has also shown that a short questionnaire as well as monetary incentives, recorded delivery and prenotification are examples that may lead to increased response to postal questionnaires. ${ }^{27}$ To increase participation in the Telemark study, a prenotification through the local newspaper and radio was conducted to inform the public that the majority of those aged 16-50 years would receive a questionnaire during the following weeks. The study was only allowed to send two reminders to the study population by REC. When assessing the reasons for not participating, the most frequent answers were no particular reason, forgot to answer and lack of time. However, $10.4 \%$ of the non-responders stated that the questionnaire was too extensive as the reason for not responding, implying that a shorter questionnaire could have increased the participation rate.

In conclusion, non-response was associated with younger age, being male, past smoking and living in rural areas. The Telemark study provided valid prevalence estimates for physician-diagnosed asthma and several respiratory symptoms despite a low response rate. However, it was necessary to adjust prevalence estimates for chronic cough and use of asthma medication to more accurately represent the sample of eligible individuals. The identified differences in exposure-outcome associations for responders compared to non-responders should be considered in future studies.

\section{Author affiliations}

${ }^{1}$ Department of Occupational and Environmental Medicine, Telemark Hospital, Skien, Norway

${ }^{2}$ Faculty of Medicine, Institute of Clinical Medicine, University of Oslo, Oslo, Norway

${ }^{3}$ National Institute for Occupational Safety and Health (NIOSH), Morgantown, West Virginia, USA

${ }^{4}$ Department of Occupational and Environmental Medicine, Sahlgrenska Academy, University of Gothenburg, Gothenburg, Sweden

${ }^{5}$ Department of Respiratory Medicine, Oslo University Hospital, Rikshospitalet, Oslo, Norway

Contributors RA, MVS, PKH, KT, JK and AKMF planned the study. RA and GFG carried out the data collection. MVS and RA performed the statistical analyses. PKH, KT, JK and AKMF helped with guidance regarding statistical analyses and helped draft the manuscript. All authors provided input on the manuscript, and read and approved the final manuscript.

Funding The study was supported by internal funds from Telemark hospital.

Disclaimer The findings and conclusions in this report are those of the authors and do not necessarily represent the views of the National Institute for Occupational Safety and Health.

Competing interests None declared.

Ethics approval The study was conducted with the approval of The Regional Committee for Medical and Health Research Ethics in Norway (REC 2012/ 1665).

Provenance and peer review Not commissioned; externally peer reviewed.

Data sharing statement No additional data are available.
Open Access This is an Open Access article distributed in accordance with the Creative Commons Attribution Non Commercial (CC BY-NC 4.0) license, which permits others to distribute, remix, adapt, build upon this work noncommercially, and license their derivative works on different terms, provided the original work is properly cited and the use is non-commercial. See: http:// creativecommons.org/licenses/by-nc/4.0/

\section{REFERENCES}

1. Braman SS. The global burden of asthma. Chest $2006 ; 130(1$ Suppl):4S-12S.

2. Asher MI, Montefort $\mathrm{S}, \mathrm{Björkstén} \mathrm{B}$, et al. Worldwide time trends in the prevalence of symptoms of asthma, allergic rhinoconjunctivitis, and eczema in childhood: ISAAC Phases One and Three repeat multicountry cross-sectional surveys. Lancet 2006;368:733-43.

3. Torén K, Gislason T, Omenaas E, et al., RHINE Group. A prospective study of asthma incidence and its predictors: the RHINE study. Eur Respir J 2004;24:942-6.

4. Thomsen SF, Ulrik CS, Kyvik KO, et al. The Incidence of asthma in young adults. Chest 2005;127:1928-34.

5. Eagan TM, Gulsvik A, Eide G, et al. Occupational airborne exposure and the incidence of respiratory symptoms and asthma. Am J Respir Crit Care Med 2002;166:933-8.

6. Torén K, Ekerljung L, Kim JL, et al. Adult-onset asthma in west Sweden-incidence, sex, differences and impact of occupational exposures. Respir Med 2011;105:1622-8.

7. Christensen Al, Ekholm O, Gray L, et al. What is wrong with non-respondents? Alcohol-, drug- and smoking related mortality and morbidity in a 12-year follow up study of respondents and non-respondents in the Danish Health and Morbidity Survey. Addiction 2015;110:1505-12.

8. Schneider KL, Clark MA, Rakowski W, et al. Evaluating the impact of non-response bias in the Behavioral Risk Factor Surveillance System (BRFSS). J Epidemiol Community Health 2012;66: 290-5.

9. Gray L, McCartney G, White IR, et al. Use of record-linkage to handle non-reponse and improve alcohol consumption estimates in health survey data: a study protocol. BMJ Open 2013;3:pii: e002647.

10. Mannetje A, Eng A, Douwes J, et al. Determinants of non-response in an occupational exposure and health survey in New Zealand. Aust N Z J Public Health 2011;35:256-63.

11. Groves RM. Nonresponse rates and nonresponse bias in household surveys. Public Opin Q 2006;70:646-75.

12. Johannessen A, Verlato G, Benediktsdottir B, et al. Longterm follow-up in European respiratory health studies-patterns and implications. BMC Pulm Med 2014;14:63.

13. Christensen Al, Ekholm O, Kristensen PL, et al. The effect of multiple reminders on response patterns in a Danish health survey. Eur J Public Health 2015;25:156-61.

14. Rönmark EP, Ekerljung L, Lötvall J, et al. Large scale questionnaire survey on respiratory health in Sweden: effects of late- and non-response. Respir Med 2009;103:1807-15.

15. Verlato G, Melotti R, Olivieri M, et al. Asthmatics and ex-smokers respond early, heavy smokers respond late to mailed surveys in Italy. Respir Med 2010;104:172-9.

16. Hazell ML, Morris JA, Linehan MF, et al. Factors influencing the response to postal questionnaire surveys about respiratory symptoms. Prim Care Respir J 2009;18:165-70.

17. Burney PG, Laitinen LA, Perdrizet $S$, et al. Validity and repeatability of the IUATLD (1984) Bronchial Symptoms Questionnaire: an international comparison. Eur Respir J 1989;2:940-5

18. Kongerud J, Vale JR, Aalen OO. Questionnaire reliability and validity for aluminium potroom workers. Scand $J$ Work Environ Health 1989;15:364-70.

19. Torén K, Brisman J, Järvholm B. Asthma and asthma-like symptoms in adults assessed by questionnaires. A literature review. Chest 1993:104:600-8.

20. ILO. International Standard Classification of Occupations ISCO 88. Geneva, Switzerland: ILO, 1991. ISBN 92-2-106438-7.

21. Höfler M, Pfister H, Lieb R, et al. The use of weights to account for non-response and drop-out. Soc Psychiatry Psychiatr Epidemiol 2005;40:291-9.

22. Brøgger J, Bakke P, Eide GE, et al. Contribution of follow-up of nonresponders to prevalence and risk estimates: a Norwegian respiratory health survey. Am J Epidemiol 2003;157:558-66.

23. Kotaniemi JT, Hassi J, Kataja M, et al. Does non-responder bias have a significant effect on the results in a postal questionnaire study? Eur J Epidemiol 2001;17:809-17. 
24. Rönmark E, Lundqvist A, Lundbäck B, et al. Non-responders to a postal questionnaire on respiratory symptoms and diseases. Eur $J$ Epidemiol 1999;15:293-9.

25. Bakke $P$, Gulsvik A, Lilleng $P$, et al. Postal survey on airbourne occupational exposure and respiratory disorders in Norway: causes and consequences of non-response. J Epidemiol Community Health 1990;44:316-32.
26. Elias P. "Occupational classification (ISCO-88): concepts, methods, reliability, validity and cross-national comparability". Paris: OECD Labour Market and Social Policy Occasional Papers, No. 20, OECD Publishing, 1997.

27. Edwards PJ, Roberts I, Clarke MJ, et al. Methods to increase response to postal and electronic questionnaires. Cochrane Database Syst Rev 2009;(3):MR000008. 